\title{
Supply Chain Management (SCM): Its Future Implications
}

\author{
Mamun Habib \\ Visiting Scholar, School of Quantitative Sciences (SQS), Universiti Utara Malaysia (UUM), Malaysia \\ Email: mamunhabib@gmail.com, md.mamun@uum.edu.my
}

Received July 2014

\begin{abstract}
This keynote paper represents theory of Supply Chain Management (SCM) and its future implications as well as demonstrates chronological prospective of SCM in terms of time frame in different areas of manufacturing and service industries. SCM has been widely researched in numerous application domains during the last decade. Despite the popularity of SCM research and applications, considerable confusion remains as to its meaning. There are several attempts made by researchers and practitioners to appropriately define SCM. Amidst fierce competition in all industries, SCM has gradually been embraced as a proven managerial approach to achieving sustainable profits and growth. Finally, this study demonstrates Educational Supply Chain Management, as the application of SCM in the service industry, which would unlock other applications of SCM in different arenas. Integrated Tertiary Educational Supply Chain Management (ITESCM) model would be verified through Structural Equation Modeling (SEM) Techniques that would describe in this paper. The ITESCM model furnishes stakeholders of the supply chain with appropriate strategies to review and appraise their performance toward fulfillment of ultimate goals, i.e. producing high-caliber graduates and high-impact research outcomes, which represent two main contributions, for the betterment of the society.
\end{abstract}

\section{Keywords}

Supply Chain Management, ITESCM, Service Industry, Education, Evolution

\section{Introduction}

Researchers usually focused on Supply chain management (SCM) issues in profit organizations during last decade. Research objectives may include adding value, reducing cost, or slashing response time in various parties involved in the manufacturing supply chain. However, very few studies were attempted in non-profit organizations. An extremely scarce number of research papers focused on SCM in the academia [1] [2].

Ref. [1] states that a profit organization attempts to maximize profits, whereas a non-profit organization considers monetary returns of less importance. Their major objectives may include improved literacy rate, better quality of life, equal opportunities for all genders or races, etc. The revenues gained by a non-profit organization would be used primarily to balance the expenditure of the organization. Due to conflicting objectives, managing a successful profit organization may be drastically different from a non-profit organization [2]. Recently, an in- 
creasingly large number of research studies highlight the criticalness of SCM as a means to assuring organizational success.

SCM assists the business organization to compete in the dynamic international market. The objective of SCM is to incorporate activities across and within organizations for providing the customer value. This should also be applicable to the academia, which represents a type of non-profit organizations. The goal is to provide the society value by producing high quality graduates and research outcomes. An integrated educational supply chain involves coordination and information sharing up and down the process among all stakeholders. With technology facilitating information flow, a coordinated supply chain can be designed to meet the strategic, planning, and operating objectives of the educational institutions. It also means establishing effective and feasible relationships both inside and outside the organization [3].

SCM is needed for various reasons: improving operations, better outsourcing, increasing profits, enhancing customer satisfaction, generating quality outcomes, tackling competitive pressures, increasing globalization, increasing importance of E-commerce, and growing complexity of supply chains. Supply chains are relatively easy to define for manufacturing industries, where each participant in the chain receives inputs from a set of suppliers, processes those inputs, and delivers them to a different set of customers. With educational institutions, one of the primary suppliers of process inputs is customers themselves, who provide their bodies, minds, belongings, or knowledge as inputs to the service processes [1] [3] [4].

This exploratory study reveals the following objectives:

- Analysis the overview of SCM through different citations and the evolution of SCM

- Presentation of ITESCM as SCM practices on tertiary educational institutions

\section{Evolution of SCM}

The supply chain literature review was conducted to study the past researches. Before the 1950s, logistics was thought of in military terms. It had to do with procurement, maintenance, and transportation of military facilities, materials, and personnel. The study and practice of physical distribution and logistics emerged in the 1960s and 1970s [1] [3].

The logistics era prior to 1950 has been characterized as the "dormant years", when logistics was not considered a strategic function. Around 1950s changes occurred that could be classified as a first "Transformation". The importance of logistics increased considerably, when physical distribution management in manufacturing firms was recognized as a separate organizational function. The SCM concept was coined in the early 1980s by consultants in logistics [3]. The authors emphasized that the supply chain must have been viewed as a single entity and that strategic decision-making at the top level was needed to manage the chain in their original formulation. This perspective is shared with logisticians as well as channel theorists in marketing [1].

SCM has become one of the most popular concepts within management in general since its introduction in the early 1980s [1]. A number of journals in manufacturing, distribution, marketing, customer management, transportation, integration, etc. published articles on SCM or SCM-related topics. The evolution of SCM continued into the 1990s due to the intense global competition [2].

Ref. [3] went as far as claiming there was a paradigm shift within the management literature: "One of the most significant changes in paradigm of modern business management is that individual businesses no longer compete as solely autonomous entities, but rather as supply chains. Business management has entered the era of inter-network competition and the ultimate success of a single business will depend on management's ability to integrate the company's intricate network of business relationships”.

Ref. [1] adopted SCM in the National Health Service. In fact, it was the first paper of SCM in the service industry. Ref. [5] explored the customer supplier duality in the service organizations as it pertained to SCM in the service industry. Ref. [6] explored supply chain application to the service industry. O'Brien and Kenneth (1996) proposed an educational supply chain as a tool for strategic planning in tertiary education. The study was based on a survey among employers and students.

Survey findings revealed that integration and coordination among students and employers should have been promoted. Ref. [7] explored a framework for SCM based on several service industries including automobile, grocery, computers, book publishing etc. According to the case study conducted at the City University of Hong Kong, Ref. [8] defined educational supply chain as the "Student" and the "Research" supply chain.

Ref. [1] represents the first large scale empirical study that systematically investigate input of the university, 
output of the university through educational SCM. This exploratory research addresses the education supply chain, the research supply chain, and educational management as major constituents in an Integrated Tertiary Educational Supply Chain Management (ITESCM) model. Its applicability was successfully verified and validated through survey data from leading tertiary educational institutions around the world. Redesigned ITESCM Model was developed in 2012 which is more users-friendly [4] [9]. The emergence and evolution of SCM may be depicted as a timeline shown in Figure 1.

\section{Research Methodology}

The analysis of this paper is based on both primary and secondary data. First part of this paper, evolution of SCM evolved Secondary data sources, particularly online databases, books, journals, conference papers, etc. On the other hand, $2^{\text {nd }}$ part of this paper furnished based on the analysis of literature, past theoretical frameworks, interviews with stakeholders. ITESCM model constructs were identified and confirmed by 493 respondents, representing university administrators, faculty and staffs, employers, and graduates. Its applicability was successfully verified and validated through survey data from leading tertiary educational institutions around the world.

\section{SCM Practices}

Supply chain management practice on the service industry has been depicted in this paper. ITESCM model denotes supply chain managements for the universities which represents one of the service industries. One of the main goals of an educational supply chain is to improve the well-being of the end customer or the society. To achieve this goal, educational institutions need to have a certain degree of knowledge about the partners in their supply chains including suppliers, customers, and the society. The performance of the supply chain management depends on the seamless coordination of all supply chain stakeholders to ensure attainment of desirable outcomes.

The ITESCM, which stands for Integrated Tertiary Educational Supply Chain Management, model represents supply chain management for the academia [1] [10]-[12]. This model depicts the integrated form of educational supply chain and educational management for the universities. Educational supply chain also consists of education supply chain and research supply chain. This paper is the revised version of ITESCM model, which represents academic supply chain management for the universities.

In academic supply chain management, raw materials are students as well as internal and external projects. Finished products are graduates and research outcomes [3] [13] [14]. Suppliers, supplied inputs, the service provider, customers, supplied outputs, and the consumer have been identified in the integrated supply chain for the universities. Figure 2 illustrates an education supply chain and a research supply chain, which together form the integrated supply chain for the universities [14] [15] [21]-[24].

In this paper, authors intend to redesign ITESCM model that is the revised form of original ITESCM. That model would be easily explicable and research equations are friendly for users who intend to apply in practical

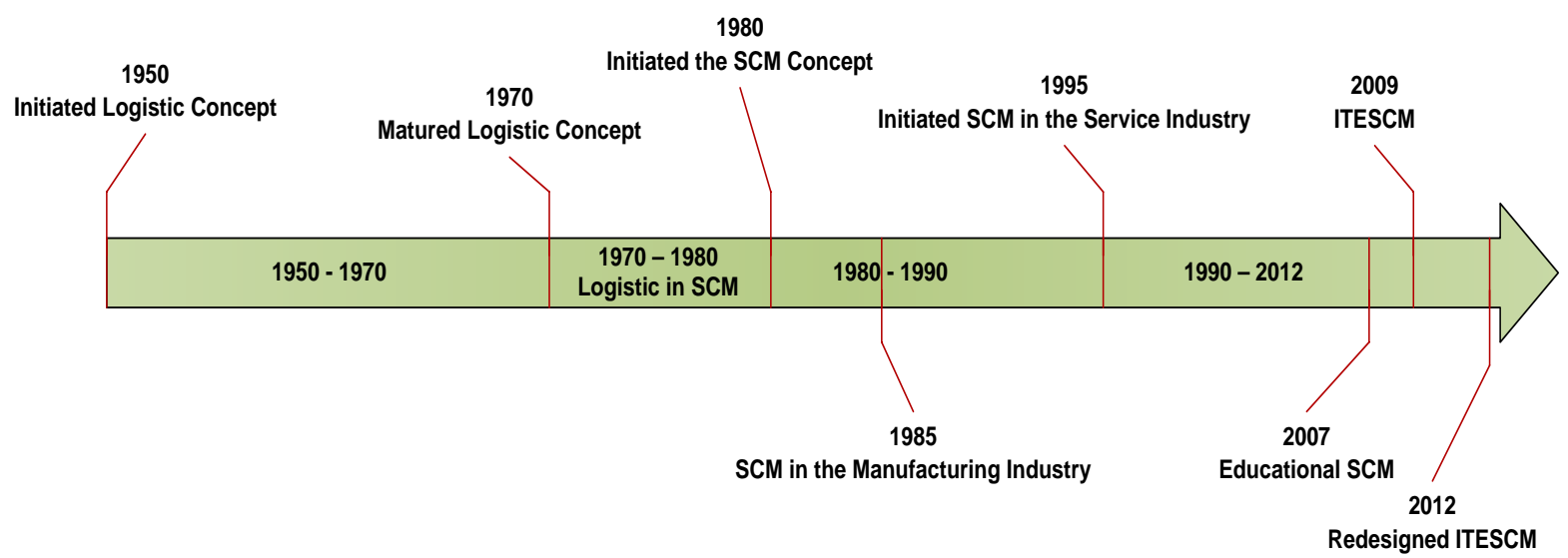

Figure 1. Evolutionary time line of supply chain management. 


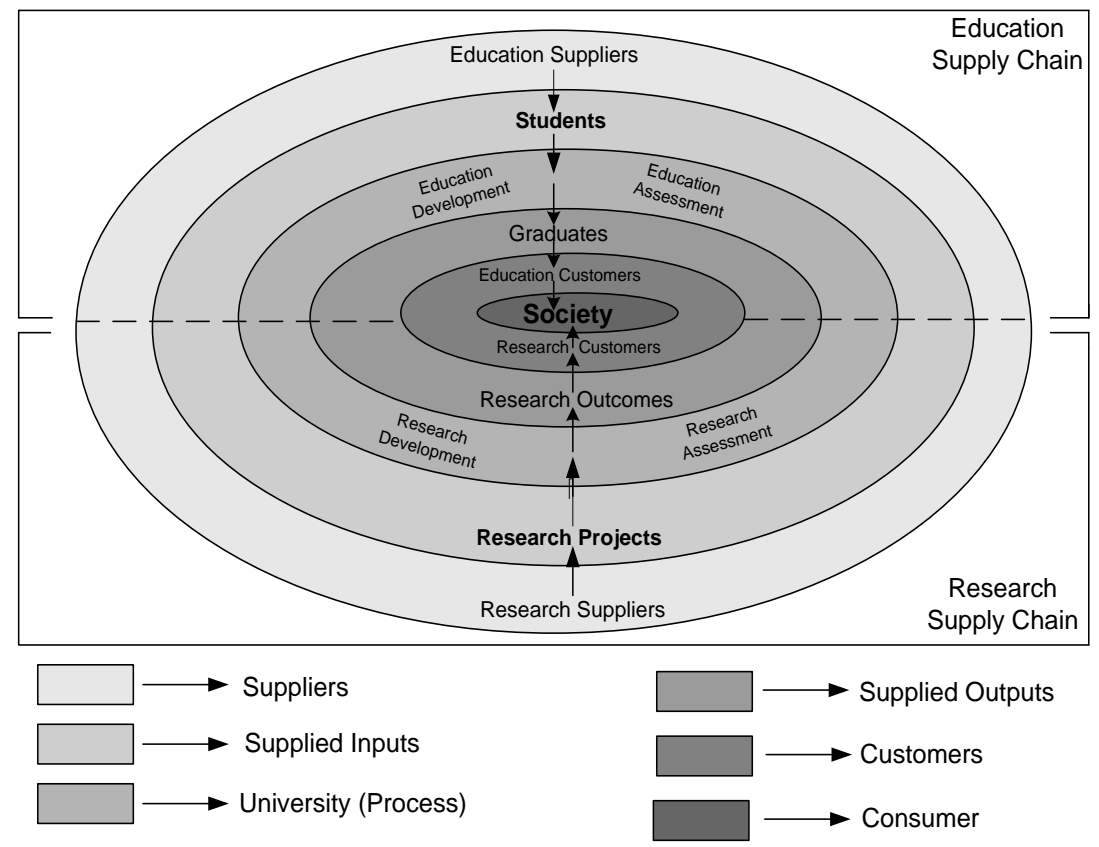

Figure 2. An integrated supply chain for the universities.

field of tertiary educational institutions. Figure 3 illustrates redesigned ITESCM model.

Different Factors in the Universities: According to the concept of three decision levels, including strategic, planning and operating, in SCM, this concept would be adopted for the higher educational institutions [4]. To accomplish proper teaching and research works in the universities; different factors have to need analyzed. Four factors, namely faculty capabilities, facilities, programs establishment, university culture [3] [10] [13] [16]-[17] will be illustrated in this section.

Programs Establishment (PE): Programs establishment would be occurred for the education and research in terms of development and assessment in the universities. Universities design different programs, to enhance the diversification in education development and establish various programs to assess the development. Universities also intend different programs to increase the diversification in research development and research assessment. Universities have to attempt product differentiation, i.e. programs establishment. Hands-on experience, industrial placements, social demand, provision of IT facilities, and innovative academic methods all demonstrate attempts to differentiate programs establishment [3] [13].

Faculty Capabilities (FC): Faculty members establish good communication, provide rich environment for classroom observation, model best practices, create opportunities for reflection, and support students' participation in curriculum planning, teaching and research. Traditionally, university faculty members are evaluated according to the three major criteria: teaching, research, and services [15].

University Culture (UC): The concept of organizational culture would be applicable for the universities by the name of University Culture. However, the type of the university culture will fully depends on the university management or administrator. In fact, university culture is the personality of the university [11] [13].

Facilities (FA): Universities offer a wide range of modern facilities to their students. These include state of the art lecture halls, libraries, laboratories and IT services to ensure that students are provided with an environment in which they can learn, both successfully and comfortably. Lecture rooms are principally conducted using state-of-the-art distance learning technology, online education, e-learning via Internet. Online databases, ejournal, digital library, etc. represents modern research facilities in the universities [3] [14].

\section{Redesigned ITESCM Model Evaluation}

The researchers pointed out six hypotheses and three models. Hypothesis $\mathrm{H}_{1}$ stands for graduates and hypothesis $\mathrm{H}_{2}$ for research outcomes. Hypotheses $\mathrm{H}_{3}, \mathrm{H}_{4}, \mathrm{H}_{5}$ and $\mathrm{H}_{6}$ for supplied outputs. The following hypotheses are established. 


\begin{tabular}{cc}
\hline $\mathrm{H}_{1}$ & There is a relationship between education development and education assessment with graduates \\
$\mathrm{H}_{2}$ & There is a relationship between research development and research assessment with research outcomes \\
$\mathrm{H}_{3}$ & There is a relationship between graduates and education customers \\
$\mathrm{H}_{4}$ & There is a relationship between research outcomes and research customers \\
$\mathrm{H}_{5}$ & There is a relationship between education customers and the society \\
$\mathrm{H}_{6}$ & There is a relationship between research customers and the society \\
\hline
\end{tabular}

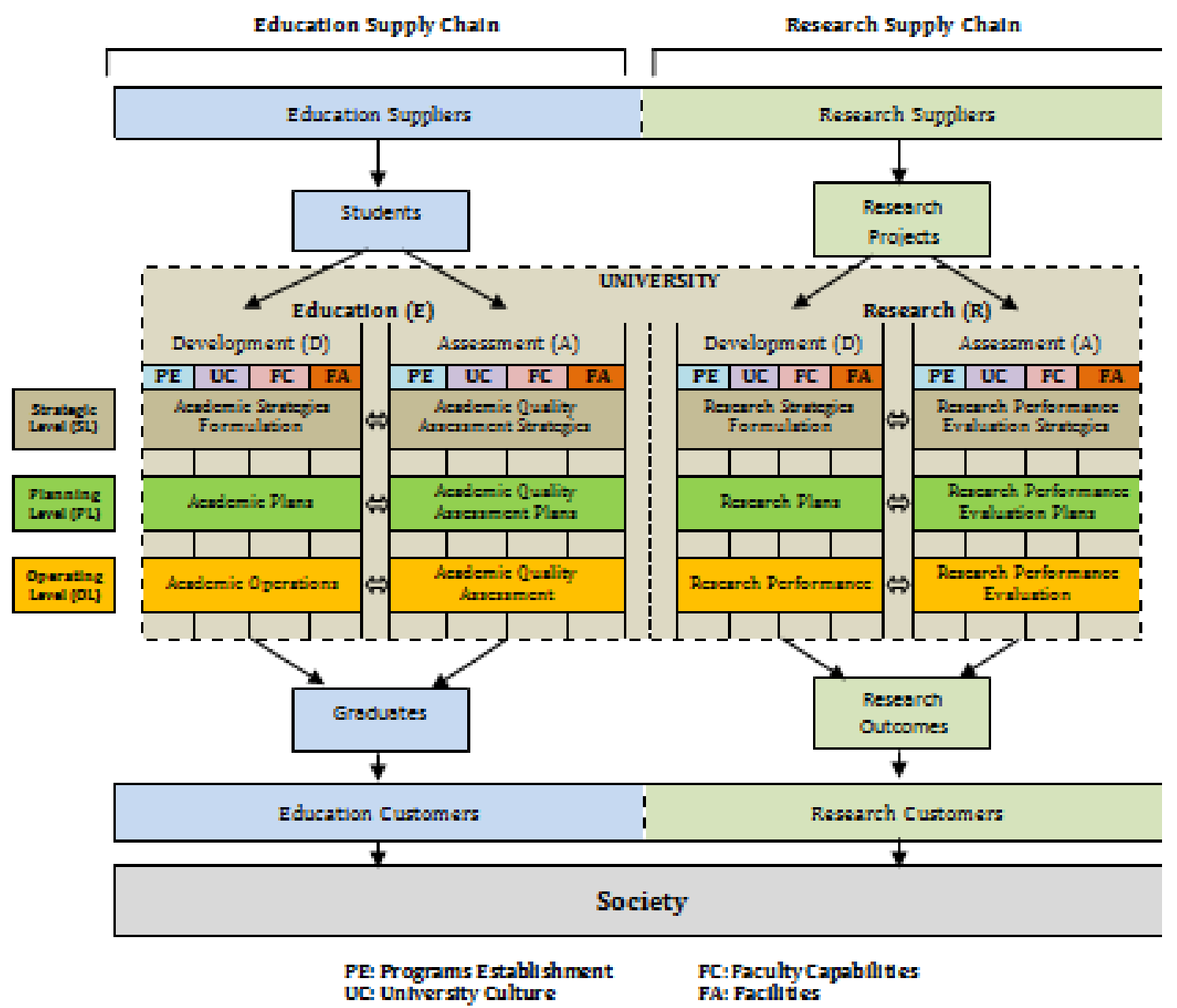

Figure 3. Redesigned ITESCM Model.

\section{Model A-Graduates}

Model A contains Education Development $\left(E_{d}\right)$ and Education Assessment $\left(E_{a}\right)$. There are four subgroups, including programs establishment $\left(E_{d P E}\right)$, university culture $\left(E_{d U C}\right)$, faculty capabilities $\left(E_{d F C}\right)$, and facilities $\left(E_{d F A}\right)$, respectively in Education Development. Similarly four subgroups are available in Education Assessment.

\section{MLR Equations}

$$
\begin{array}{r}
E_{d}=0.63 E_{d P E}+0.70 E_{d U C}+0.65 E_{d F C}+0.65 E_{d F A} \\
\mathrm{E}_{\mathrm{a}}=0.68 E_{a P E}+0.74 E_{a U C}+0.69 E_{a F C}+0.66 E_{a F A} \\
\text { Graduates }=0.97 E_{d}+0.92 E_{a}
\end{array}
$$

Equation (3) depicts that education development is highly contributed to produce quality graduates in the 


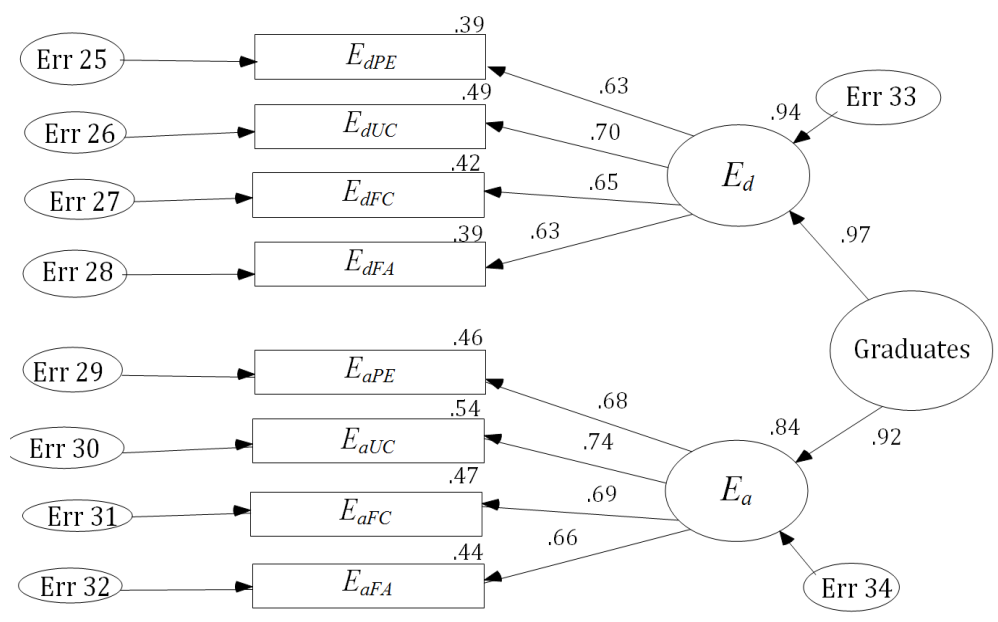

Figure 4. AMOS Graphics Output of Model A (Standardized Estimates).

universities.

$$
\begin{gathered}
\text { Graduates }=0.97 E_{d}+0.92 E_{a} \\
=0.97\left[0.63 E_{d P E}+0.70 E_{d U C}+0.65 E_{d F C}+0.65 E_{d F A}\right] \\
+0.92\left[0.68 E_{a P E}+0.74 E_{a U C}+0.69 E_{a F C}+0.66 E_{a F A}\right] \\
=0.61 E_{d P E}+0.68 E_{d U C}+0.63 E_{d F C}+0.61 E_{d F A} \\
+0.63 E_{a P E}+0.68 E_{a U C}+0.63 E_{a F C}+0.61 E_{a F A}
\end{gathered}
$$

The above equation shows university culture at education development and education assessment is highly contributed to produce the graduates in the universities.

Model Fit Index: Chi-square $=8.936$ (Ratio of relative chi-square close to 5 indicates reasonable fit) [18] [20], Degrees of freedom $=19$, Probability level $=0.000$, RMSEA $=0.127$ NFI $=0.880$, CFI $=0.891$ (NFI and CFI values close to 1 indicate a very good fit) [3] [13].

The above equations, graphics output (Figure 4), Model fit index, and above all statistical discussion on AMOS magnifies that hypothesis $\mathrm{H}_{1}$ fails to reject and states that there are significant relationship between education development and graduates as well as education assessment and graduates.

\section{Model B-Research Outcomes}

Model B contains Research Development $\left(\mathrm{R}_{\mathrm{d}}\right)$ and Research Assessment $\left(\mathrm{R}_{\mathrm{a}}\right)$. There are four subgroups, including programs establishment $\left(R_{d P E}\right)$, university culture $\left(R_{d U C}\right)$, faculty capabilities $\left(R_{d F C}\right)$, and facilities $\left(R_{d F A}\right)$, respectively in Research Development. Similarly four subgroups are available in Research Assessment.

\section{MLR Equations}

$$
\begin{array}{r}
R_{d}=0.60 R_{d P E}+0.71 R_{d U C}+0.63 R_{d F C}+0.67 R_{d F A} \\
R_{a}=0.67 R_{a P E}+0.72 R_{a U C}+0.64 R_{a F C}+0.69 R_{a F A} \\
\text { Research Outcomes }=0.99 R_{d}+0.89 R_{a}
\end{array}
$$

From the research findings, Equation (6) depicts that research development is highly contributed to produce research outcomes in the universities. From Equation (6),

$$
\begin{gathered}
\text { Research Outcomes }=0.99\left[0.60 R_{d P E}+0.71 R_{d U C}+0.63 R_{d F C}+0.67 R_{d F A}\right] \\
+0.89\left[0.67 R_{a P E}+0.72 R_{a U C}+0.64 R_{a F C}+0.69 R_{a F A}\right] \\
=0.59 R_{d P E}+0.70 R_{d U C}+0.62 R_{d F C}+0.66 R_{d F A} \\
+0.60 R_{a P E}+0.64 R_{a U C}+0.66 R_{a F C}+0.61 R_{a F A}
\end{gathered}
$$

From the research results of Equation (7), university culture and facilities in research development as well as faculty capabilities in research assessment are highly contributed to produce the research outcomes in the universities.

Model Fit Index: Chi-square $=9.991$, Degrees of freedom $=19$, Probability level $=0.000$, RMSEA $=0.135$, $\mathrm{NFI}=0.872$, $\mathrm{CFI}=0.883$

The above equations, graphics output (Figure 5), Model fit index and above all statistical discussion on 


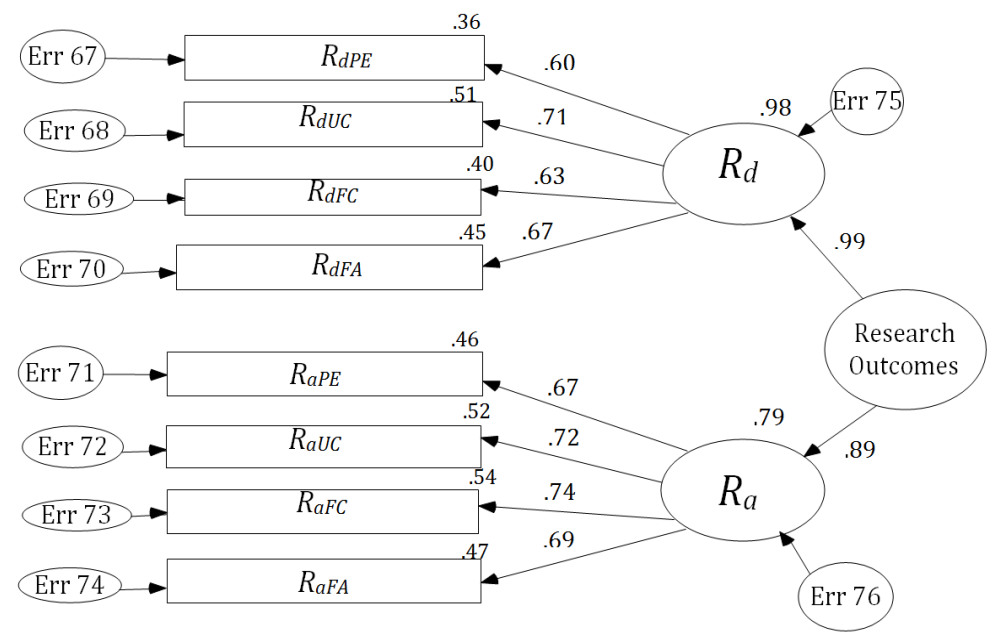

Figure 5. AMOS Graphics Output of Model B (Standardized Estimates).

AMOS rectifies that hypothesis $\mathrm{H}_{2}$ fails to reject and states that there are significant relationship between research development and research outcomes as well as research assessment and research outcomes.

\section{Model C-Supplied Outputs}

Model C is representing the inter relationships among different variables to justify the hypotheses $\mathrm{H}_{3}, \mathrm{H}_{4}, \mathrm{H}_{5}$ and $\mathrm{H}_{6}$ by SEM through AMOS.

\section{MLR Equations}

$$
\begin{aligned}
& \text { Society }=0.61 \text { EducationCustomers }+0.61 \text { ResearchCustomers } \\
& =0.61 \text { [0.34Graduates }]+0.61 \text { [0.15ResearchOutcomes }] \\
& =0.21 \text { Graduates }+0.09 \text { ResearchOutcomes }
\end{aligned}
$$

From the research findings, the society consists of graduates and research outcomes. The author defined the society as the function of graduates and research outcomes.

Society $=\mathrm{f}$ (Graduates, Research Outcomes)

The equation (8) represents that graduates are highly contributed to the society. This equation also depicts that education customers and research customers have equal contribution to the society.

$$
\begin{aligned}
\text { Society } & =0.21\left[0.97 E_{d}+0.92 E_{a}\right]+0.09\left[0.99 R_{d}+0.89 R_{a}\right] \\
& =0.20 E_{d}+0.19 E_{a}+0.09 R_{d}+0.08 R_{a}
\end{aligned}
$$

The above equation represents the relationship between the society and education development, education assessment, research development, research assessment. Education development and then education assessment are highly contributed to the society.

$$
\begin{aligned}
& \text { Society }=0.20\left[0.63 E_{d P E}+0.70 E_{d U C}+0.65 E_{d F C}+0.65 E_{d F A}\right] \\
& \quad+0.19\left[0.68 E_{a P E}+0.74 E_{a U C}+0.69 E_{a F C}+0.66 E_{a F A}\right] \\
& \quad+0.09\left[0.60 R_{d P E}+0.71 R_{d U C}+0.63 R_{d F C}+0.67 R_{d F A}\right] \\
& \quad+0.08\left[0.67 R_{a P E}+0.72 R_{a U C}+0.64 R_{a F C}+0.69 R_{a F A}\right] \\
& \text { Society }=0.126 E_{d P E}+0.14 E_{d U C}+0.13 E_{d F C}+0.126 E_{d F A} \\
& \quad+0.129 E_{a P E}+0.141 E_{a U C}+0.131 E_{a F C}+0.125 E_{a F A} \\
& +0.054 R_{d P E}+0.064 R_{d U C}+0.057 R_{d F C}+0.06 R_{d F A}+0.054 R_{a P E} \\
& +0.058 R_{a U C}+0.059 R_{a F C}+0.055 R_{a F A}
\end{aligned}
$$

Model Fit Index: Chi-square $=5.494$, Degrees of freedom $=3$, Probability level $=0.001$, RMSEA $=0.096$, $\mathrm{NFI}=0.896$, CFI $=0.911$

Equations, graphics output (Figure 6), Model fit index, and above all statistical discussion on AMOS states that there are significant relationships between graduates and education customers, research outcomes and research customers. There are also significant relationships among education customers, research customers and the society. There- fore, hypotheses $\mathrm{H}_{3}, \mathrm{H}_{4}, \mathrm{H}_{5}$ and $\mathrm{H}_{6}$ fail to reject. 


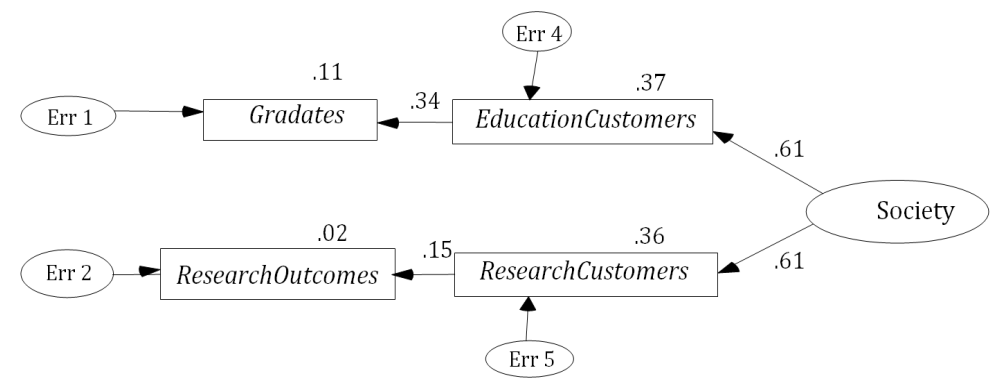

Figure 6. AMOS Graphics Output of Model C (Standardized Estimates).

\section{Implications of Redesigned ITESCM}

Integrated Tertiary Educational Supply Chain Management (ITESCM) model was developed by Habib in 2009 [3] [13]. Due to receiving feedback from academicians and practitioners, the researchers attempt to revise ITESCM model to comply it in real-life application for different universities in the world. Redesigned model is user friendly and easy to understand for current university administrators and prospective investigators.

If the researcher chooses 5 (strongly agree of 5 point Likert Scale) for each function in Equation (10), in that case, the maximum value of Equation (10) will equal to 7.545. On the other hand, if the investigator selects 1 (strongly disagree) for each function in the equation, in that case, the minimum value of Equation (10) will equal to $\mathbf{1 . 5 0 9}$. Then, the researcher suggests cut off the value for the function of the society at fifty percent is $\mathbf{4 . 5 2 7}$ to indicate the value can be accepted.

$$
\text { UniversityOutcomes }=\frac{\text { Society }-1.509}{7.545-1.509} *(100-0)
$$

The resulting suitability index, University Outcomes in equation (11) ranges from $0 \%$ to $100 \%$ with $0 \%$ being the least favorable and $100 \%$ being the most suitable. The index of at least $50 \%$ may serve as a rough acceptance criterion for the well-being society [13] [19].

\section{Conclusions}

This paper encompasses the evolution of SCM in terms of time frame. In addition, this research represents the first large scale empirical study that systematically investigate input, output and process of the tertiary academic institutions through redesigned ITESCM model. This empirical study based on 493 respondents from all stakeholders, including experts and administrators, faculty members and staffs of the university, employers, graduates, etc. The hypotheses testing and SEM technique through AMOS were also applied.

This paper proposes the model of academic supply chain management for the tertiary educational institutions. This model links educational management with general business management. From a managerial point of view, this research provides a novel approach to developing and assessing supply chain management application in the academia.

\section{References}

[1] Habib, M.M. (2011) Supply Chain Management (SCM): Theory and Evolution. Supply Chain Management, Applications and Simulations. InTech Open Access, Croatia, September 2011.

[2] Habib, M.M. (2010) Supply Chain Management: Theory and Its Future Perspectives. International Journal of Business, Management and Social Sciences (IJBMSS), Vol. 1.

[3] Habib, M. (2009) An Integrated Educational Supply Chain Management (ITESCM). Ph.D. Dissertation, Graduate School of Information Technology, Assumption University of Thailand, December, 2009

[4] Pathik, B.B. and Habib, M.M. (2012) Redesigned ITESCM Model: An Academic SCM for the Universities. International Journal of Supply Chain Management, ExcelingTech Publisher, UK.

[5] Sampson, S.E. (2000) Customer-supplier duality and bidirectional supply chains in service organization. International Journal of Service Industry Management, 11, 348-364. http://dx.doi.org/10.1108/09564230010355377

[6] Kathawala, Y. and Abdou, K. (2003) Supply Chain Evaluation in the Service Industry: A Framework Development 
Compared to Manufacturing. Managerial Auditing Journal, 18, 140-149. http://dx.doi.org/10.1108/02686900310455137

[7] Cigolini, R., Cozzi, M. and Perona, M. (2004) A New Framework for Supply Chain Management. International Journal of Operations \& Production Management, 24, 7-41. http://dx.doi.org/10.1108/01443570410510979

[8] Lau, A.K.W. (2007) Educational Supply Chain Management: A Case Study. On the Horizon, 15, 15-27. http://dx.doi.org/10.1108/10748120710735239

[9] Pathik, B.B., Habib, M.M. and Chowdhury, M.T. (2012) A Descriptive Study on Supply Chain Management Model for the Academia. The 6th IEEE Conference of Management of Innovation and Technology, Indonesia.

[10] Habib, M. (2010) An Empirical Research of ITESCM (Integrated Tertiary Educational Supply Chain Management) Model. Management and Services.

[11] Habib, M.M. (2011) An Exploratory Research on Educational Supply Chain Management. The IEEE International Conference on Industrial Engineering and Engineering Management (IEEM), Singapore, December 2011.

[12] Pathik, B.B., Habib, M.M. and Chowdhury, M.T. (2012) Analysis of Educational Supply Chain Management Model: A Case Study Approach. Proceedings of the 2012 International Conference on Industrial Engineering and Operations Management, Turkey.

[13] Habib, M. (2010) Supply Chain Management for Academia. LAP Lambert Academic Publishing, Germany.

[14] Habib, M. and Jungthirapanich, C. (2010) An Empirical Research of Educational Supply Chain for the Universities. The 5th IEEE International Conference on Management of Innovation and Technology.

[15] Habib, M. and Jungthirapanich, C. (2010) An Empirical Study of Educational Supply Chain Management for the Universities. INFORMS International Conference on Industrial Engineering and Operations Management, Bangladesh.

[16] Habib, M. and Jungthirapanich, C. (2010) An Empirical Research of Integrated Educational Management for the Universities. The 2nd IEEE International Conference on Information Management and Engineering, China.

[17] Habib, M.M. (2011) An Exploratory Study of Supply Chain Management for Tertiary Educational Institutions. IEEE International Technology Management Conference (ITMC), San Jose, 27-30 June 2011, 957-963.

[18] Bentler, P.M. (1990) Comparative Fit Indexes in Structural Models. Psychological Bulletin, 107, $238-246$. http://dx.doi.org/10.1037/0033-2909.107.2.238

[19] Habib, M.M. and Pathik, B.B. (2012) Academic Supply Chain Management for Tertiary Educational Institutions. The IEEE International Conference on Industrial Engineering and Engineering Management (IEEM), Hong Kong.

[20] Arbuckle, J.L. (2005) Amos ${ }^{\mathrm{TM}} 6.0$ User’s Guide. Amos Development Corporation, USA.

[21] Habib, M. and Jungthirapanich, C. (2008) An Integrated Framework for Research and Education Supply Chain for the Universities. IEEE International Conference on Management of Innovation and Technology, Thailand, September 2008, 1027-1032.

[22] Habib, M. and Jungthirapanich, C. (2009) Integrated Educational Management for the Universities. The Journal of China-USA Business Review, 8, 25-38.

[23] Habib, M. and Jungthirapanich, C. (2009) Research Framework of Educational Supply Chain Management for the Universities. IEEE International Conference on Engineering Management and Service Sciences EMS, China, September 2009.

[24] Habib, M.M. (2011) An Exploratory Analysis of Educational Management for the Universities. International Journal of Engineering, Business, Management (IJEBM), 3, 16-24. 